SURFICIAL GEOLOGIC MAP OF THE DOVER EAST QUADRANGLE IN NEW HAMPSHTPE BY GRAHAME J. LARSON AND RICHARD GOLDSMITH DESCRIPTION OF MAP UNITS

A laver of windoloun sand and silt, generally mixed with underlyit
glacial deposits, is present over most of the map area but is not
showid.

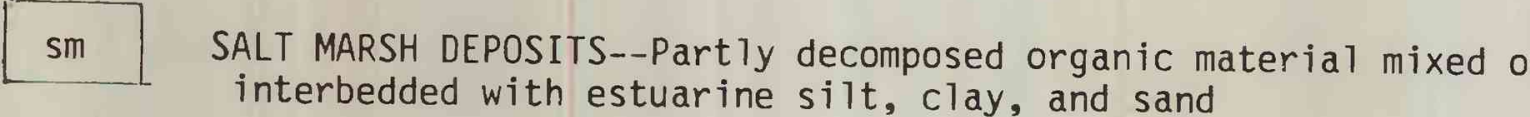

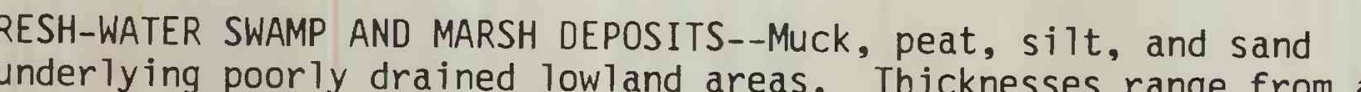

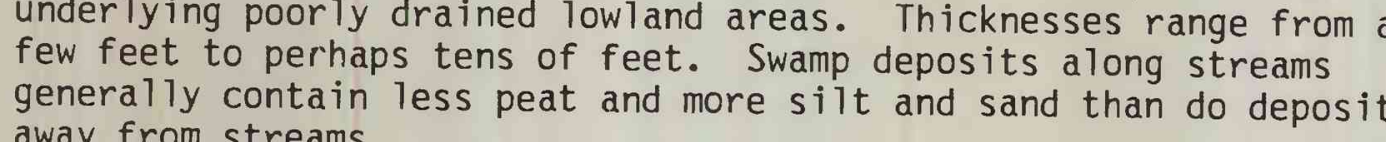

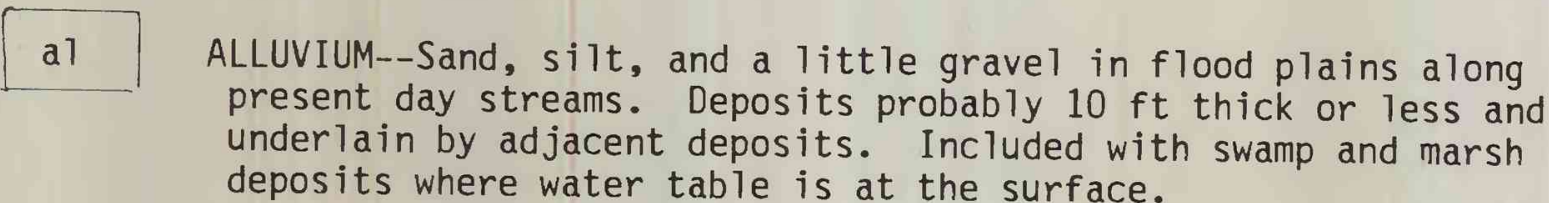

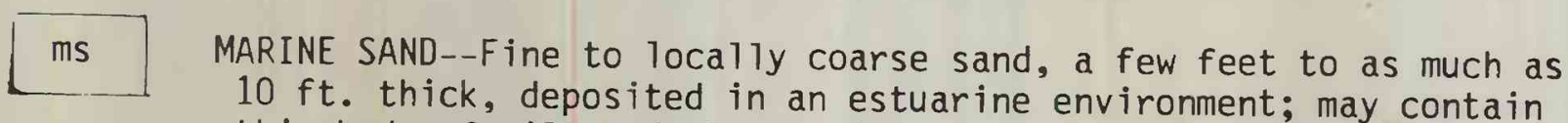
thin beds of silt and clayey sitt. Generally intertio es dounmard
and seaward with marine silt and clay (msc) and in places formus a

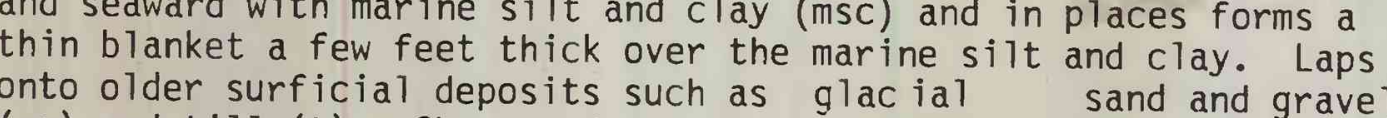

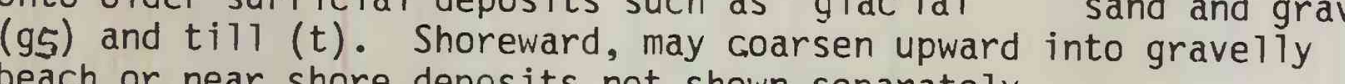



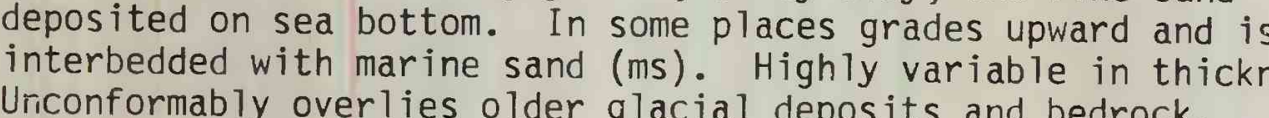

marine sano, ano silt and Clay unoffFerentiated.

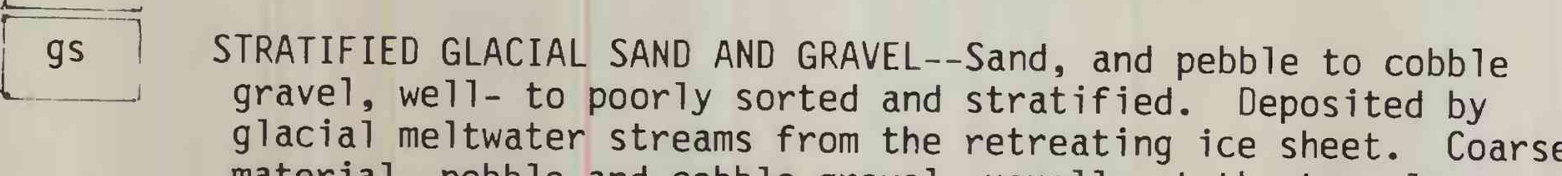

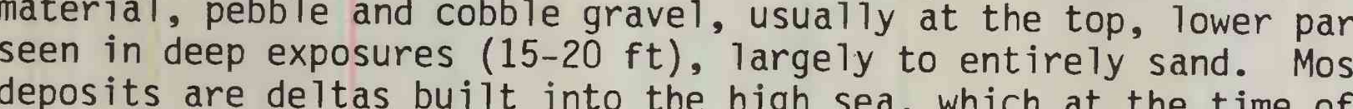

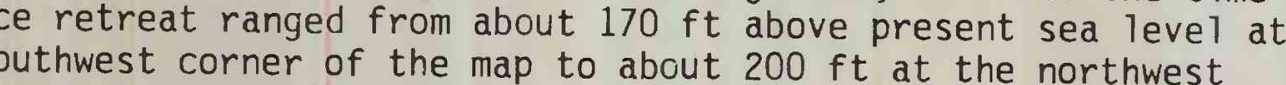
successive northward-retreat in ing pos sitions of of the the mouth of 作

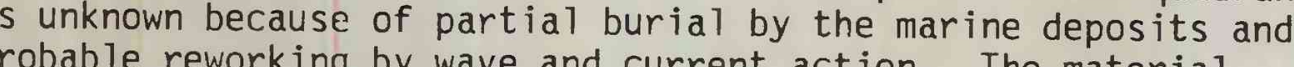
reworked is not separated on the map.


作

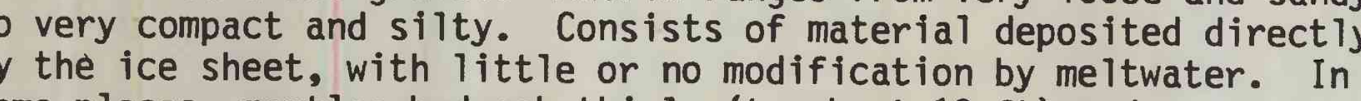
some places, mantles bedrock thinly (to about $10 \mathrm{ft}$ )
iscont inuously. In

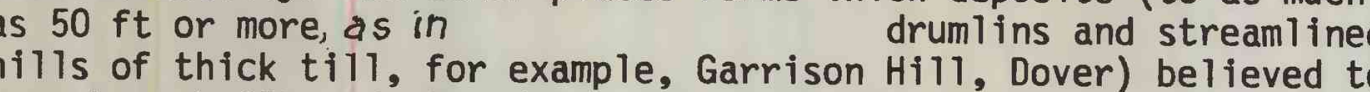

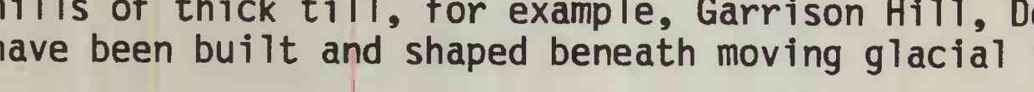

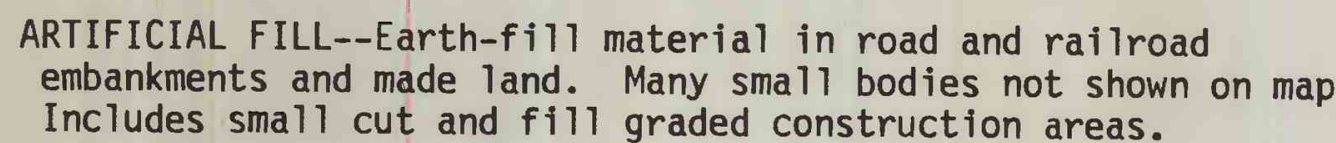

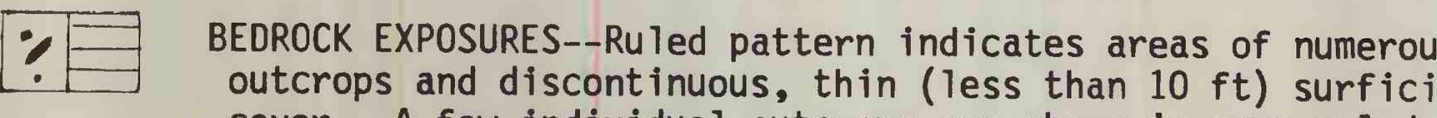

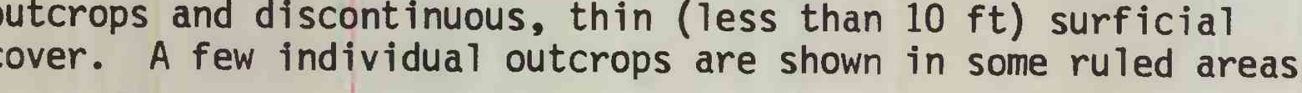



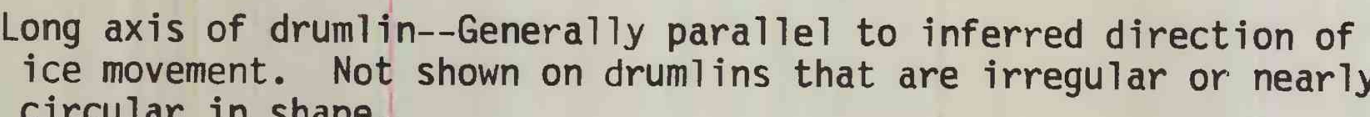

Direction of dip of delta foreset beds

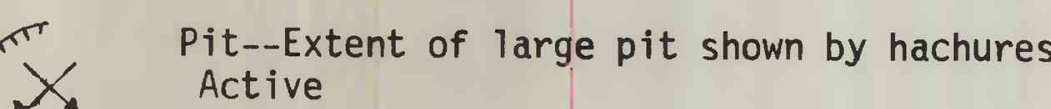

z

Well or test boring reported as ending at or in bedrock. Munber is
depth to bedrock. Alti itude of bedrock surface in feet above mean



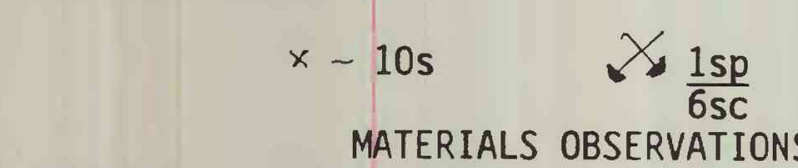

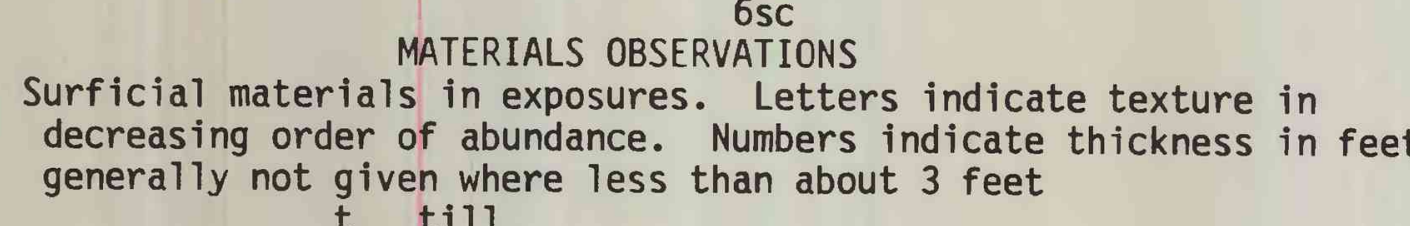

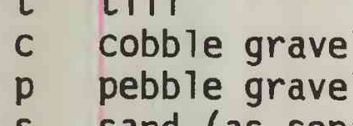

in matrix of gravel)
sit silty clay and clayey silt

\section{(a)}

Mixed sand and gravel; predominately sand in the Dover East
quadrangle

Sand, minor si

CORRELATION OF MAP UNITS



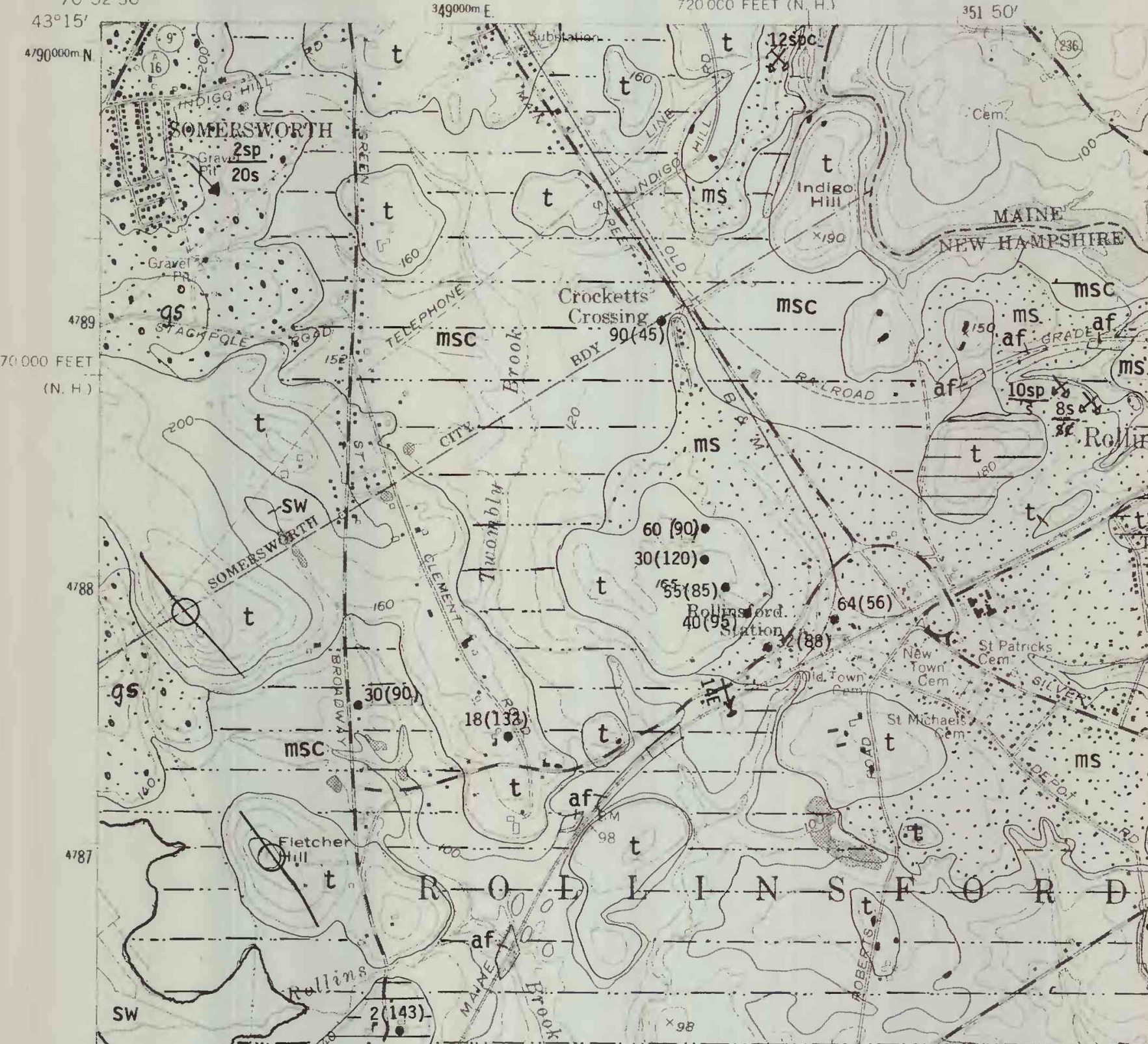
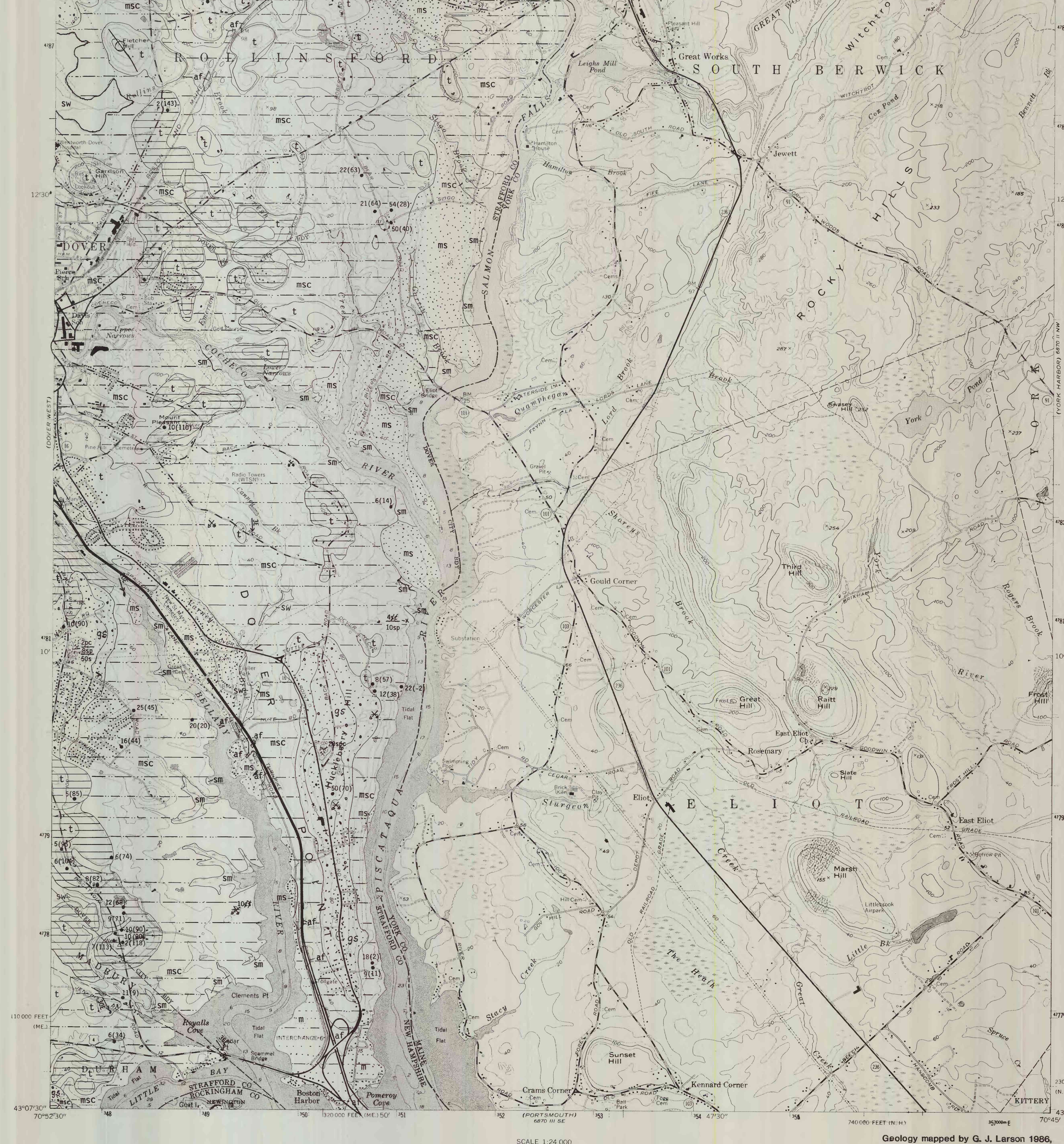

modiligh R. Roldmith 1988

\title{
SURFICIAL GEOLOGIC MAP OF THE DOVER EAST QUADRANGLE IN NEW HAMPSHIRE
}

